\title{
When quotes matter: impact of outside quotes in a science press release on news judgment
}

\section{Paige Brown Jarreau}

\begin{abstract}
Scientists often cite discrepancy between scientific values and news values as a primary factor in poor quality science reporting. The goal of this study was to understand how news values including conflict and controversy affect science communicators' evaluation of press releases containing quotes from outside expert sources. Results of an online survey experiment suggest science communicators find a climate science press release with an outside expert quote that introduces controversy to be more newsworthy. However, when a science communicator attributes relatively high importance to reliability of facts as a guiding principle in story selection, this preference for controversy is reversed.
\end{abstract}

KEywords: Science Communication, Public Relations, News Factors

\section{Introduction}

"It seems rather than highlighting the complexities, messiness and uncertainties in science to the media, the science PR machine has resulted in a sanitized, overly positive presentation of research findings" - The peril of the press release [1].

Today's rapidly evolving digital science communication environment is blurring the lines between the science journalist, the popular science communicator outside of mainstream journalism and the science public relations writer [2-4]. Increasingly, the science public relations writer is a former science reporter, and the science press release is direct reading material for science enthusiasts. Sites such as ScienceDaily ${ }^{1}$ and EurekAlert, ${ }^{2}$ as well as many science news aggregators and news sites, are today featuring slightly modified versions of science press releases for public consumption. In a recent edition of the Journal of Science Communication, Charlotte Autzen writes that the press release has become "an integrated part of science communication", [5] and that press releases today are being "copy-pasted" into newspapers and on popular internet media platforms. It is in the context of such a media environment that I ask how science press releases might incorporate more elements of rigorous science news stories. Such elements include contextual

\footnotetext{
${ }^{1}$ WWW.sciencedaily.com.

${ }^{2}$ www.eurekalert.org.
} 
evidence in the form of quotes from outside expert sources. In an era when many journalists are copy-pasting press releases from scientific institutions, science public relations writers have a chance to make a major difference in the quality of news about scientific research online [6]. In this paper, I investigate how contextual elements such as outside expert quotes, when incorporated in a science press release, affect the news decisions of popular science communicators writing for a variety of media platforms. This is an important and yet under-researched question in the context of a media environment where many scientists and science communicators are increasingly asking how we might improve science press releases based on science writer and reader demands [7]. According to a ScienceOnline2013 session titled Working towards better press releases, in a media environment where press releases are becoming "an increasingly powerful force in driving online science coverage", [1] the following questions are critical to improving science PR writing: how useful is it for public information officers (PIOs) to provide independent experts quotes for context? How much effort should be spent producing deeper context in press release articles written for public audiences? [7, 8].

\section{Objective}

The goal of this study is to find out how a climate science press release with or without important contextual information - in this case a quote from an outside expert introducing reliability or controversy to a set of scientific findings - influences science communicators' likelihood to cover the story. I investigate how quotes from outside scientific sources in press releases can introduce particular news factors to the science, such as conflict, controversy or reliability of facts, and how the introduction of these news factors can affect decisions of whether to cover the story. By an outside scientific expert, I am referring to a scientist who is an expert in the field but not involved in the research being covered in the press release. Via an online survey experiment distributed among active popular science communicators in the field, I investigate whether quotes from an outside expert in a press release can introduce particular news factors that influence news decisions. I ask also whether this influence depends in turn on the importance the individual science communicator ascribes to particular news values. I examine the influence of outside expert quotes on science communicators' likelihood to cover the story, where the outside expert quotes introduce either reliability of facts or controversy (two separate news factors) to the story by either a) confirming or b) disconfirming the findings of the primary researcher(s). I have conceptualized a disconfirming quote as one that introduces doubt and controversy to the interpretation of the primary findings in the press release. A confirming quote, on the other hand, introduces more certainty and reliability to the primary findings communicated in the press release.

This study addresses a gap in previous research. Jean Brechman and colleagues recently set out a clear need for "systematic assessment" of the process by which science is communicated to the lay public, from laboratory to news story, through the intermediary press release [9]. While Brechman and colleagues have investigated the role of 
the press release in science news coverage through qualitative investigation and content analysis, and others have conducted case studies demonstrating how press releases affect science news [10], experimental investigations such as that undertaken in this study are virtually nonexistent.

\section{Context}

\section{Definition of a science communicator}

The term "science communicator" is defined here to include science writers, science journalists, magazine writers and editors, scientific journal editorial and news article writers, science bloggers, podcasters, radio-based science reporters and other individuals who produce science content for a lay public. Such science communicators may occupy paid or non-paid positions. A broad definition of the science communicator is adopted herein, as in recent years the line between science journalists, science bloggers and other science writers who produce "newsy" content for a lay public has blurred. Many science bloggers produce freelance content for traditional media, including newspapers and magazines, while many science journalists also maintain blogs.

\section{Science values versus news values}

Problems in science reporting have been attributed to the conflicting values in science vs. journalism $[11,12]$. News values, here conceptualized as the importance journalists attribute to different news factors, influence story selection [13] and drive news coverage [14]. News factors, a term often used synonymously with news values, describe "why a topic is newsworthy and therefore published by the media" [15]. News values are typically independent, and often even counter, to the values members of the scientific community take for granted. For example, while journalists may judge newsworthiness according to the presence of new and unexpected findings [14], or the presence of controversial or conflicting findings, scientists value successful replication, reliability of research results and "endorsement by professional colleagues" [16]-[18].

Traditional news factors, or newsworthiness criteria [19]-[21], include timeliness, novelty or threshold, unexpectedness, facticity or reliability of facts, unambiguity, prominence, proximity, human interest, significance, meaningfulness, negativity, conflict or controversy, relevance to the reader, actuality and triggers [15, 22-27]. A previous finding that is especially relevant in this study is that science that is unusual or controversial is typically more visible in media [28]. Stryker [28] found some evidence that journal articles that explicitly overturn existing medical evidence garner more media coverage than articles without contextual information about existing evidence.

Recent research has also confirmed that popular science communicators often use news factors of unexpectedness, astonishment, differences of opinion, controversy and reader relevance as primary criteria in their selection and production of science news stories [15]. 
Scientific relevance, or the relevance of a new study to the overall progress of a particular field of science, has also been shown to be an important factor in story selection for science journalists [15]. However, in selecting stories, popular science communicators are likely to consider the interests of general audiences, with a focus on stories that are unexpected, exciting or dramatic, over scientific relevance. This may be especially true for those writing for digital platforms that rely directly on social network referrals. Partisan blogs increasingly focus on controversial science-policy topics, meaning that scientific issues "are frequently presented as a battle between dueling experts at two extremes, an approach that gives a false sense of balance and often overemphasizes minority views" [29]. In 2005, Geller and colleagues found in interviews with scientists and science writers that both groups place high priority on accuracy of media reports [12], related to the news factor of reliability of facts and the scientific values of replication and reliability. However, science writers assigned a higher priority than scientists to novelty, entertainment and relevance to readers.

For science communicators, especially traditional journalists, "today's newsworthy discoveries must relate to common diseases, to some immediate therapeutic application, or involve some controversy" [12]. The conflict/controversy news factor may be an especially important guiding criterion in modern environmental science coverage [30]. Boykoff and Boykoff have argued that controversy-based news factors, and the news norm of presenting a diversity of views, have led to informational bias in environmental science reporting. But while most journalists - in their aim to entertain readers and avoid repetition - are attracted to "stories that feature controversy and to new, even tentative, results that carry exciting potential" [31], science communicators who place high importance on reliability of facts over other news factors may avoid heavy coverage of new research studies containing unprecedented, unexpected or controversial results, at least until replication shows results to be reliable.

Science journalists' selection of newsworthy issues is a product of professional norms, educational background and social biases, all of which traditionally vary significantly across individuals [16]. I thus expect science communicators' news values, or the relative importance they attribute to various news factors in their determination of newsworthiness, to vary significantly across individuals. Many modern science bloggers are current or former scientists who have turned to the communication of science as a hobby or profession. At the same time, many modern press journalists who cover science and technology write about science only part of the time, without formal training in the field of science which they cover. The part-time science journalist, the specialized science journalist and the scientist blogger are likely to bring very different perspectives and concepts of newsworthiness to potential stories. For example, they may ascribe different levels of importance to traditional news factors such as conflict and controversy, due to their differing interpretations of what controversy means for science and how the public is likely to understand (or misunderstand) the results. Thus, this study considers the importance that science communicators' ascribe to a variety of traditional news factors as moderators of news judgments toward an experimentally manipulated press release. 


\section{The role of the press release in science communication}

Scientists often complain of sensationalism and controversy in coverage of science where they would rather see focus on topics of scientific consensus [32] and informed interpretations of health, environmental and other scientific issues. Scientists also caution against the broad interpretation of new and preliminary scientific information, especially if that information overturns previous evidence for the first time [18, 33]. However, while scientists often blame the media for focusing on controversy in some cases (especially in climate science) and preliminary results in other cases, research has revealed the press release as a major point of distortion in the translation of science from journal article to media story [34]. Sensationalism in science reporting may have roots in newsroom values for novelty and controversy, but press releases highlighting — instead of cautioning against - preliminary or controversial results [18, 35-37] may lead to sensationalized news coverage. Press releases have served and still serve as a major source of story ideas for science communicators in both traditional and new media environments $[2,22,25,38$ 41], and the press release "seems to both stimulate and shape news coverage" [42]. Aggregator sites such as ScienceDaily have also made science press releases more visible and accessible to not only professional news writers, but also bloggers and lay readers. This implies that the writers of science press releases should start considering including relevant contextual information, such as external evidence and quotes from outside experts. According to Karl Leif Bates, long-time science reporter and Director of Research Communications at Duke University, “[i]t's still easier to just do a lazy single-source, single-perspective story, but I'm thinking we owe the public a higher standard now that we're essentially practicing open market, capital J, journalism". ${ }^{3}$ The science press release is under increasing pressure to change. Many science PIOs are increasingly practicing writing for the lay reader and packaging press releases with images, graphics, videos and headlines designed to help spread the story via social media. According to Bates, including a quote from an outside expert in a press release is important to providing a richer context and showing the process of science, even if the quote brings the primary research results under some scrutiny [43]. So, while to date including a disconfirming outside quote in a science press release is relatively uncommon, there is demand for this type of contextual evidence in science press releases. The question that this study seeks to address is how including this type of information in a press release influences science communicators' decisions to cover the story. Exactly how and what aspects of scientific press releases influence the presence and quality of subsequent news coverage remains relatively unknown. One might anticipate that press release characteristics that increase perceived newsworthiness, such as the introduction of controversy to new climate science research, might lead to greater likelihood of prominent news coverage [21]. This may only be true, however, for science communicators who place relatively high importance on controversy as a criteria of newsworthiness, or who are embedded in a media environment that emphasizes this news value.

\footnotetext{
${ }^{3}$ Quote from a personal e-mail correspondence with the author, cited here with permission.
} 


\section{Hypotheses}

In this study, I measure perceived newsworthiness and likelihood to cover the story based on science communicators' reading of an experimentally manipulated climate science press release. According to the scientific value of replication and the news factor of reliability of facts, conflicting contextual evidence in the form of a disconfirming outside expert quote in the press release should decrease perceived newsworthiness and therefore likelihood to cover the story. At the same time, supporting contextual evidence in the form of a confirming outside expert quote should increase perceived reliability and likelihood to cover the story. However, the traditional journalistic news factor of controversy is expected to lead to greater perceived newsworthiness and therefore likelihood to cover the story when the press release includes a disconfirming quote from an outside expert. Thus I factor into this analysis the overarching importance ratings a science communicator gives to both reliability of facts and controversy as guiding news factors.

H1. Science communicators who rate conflict/controversy as very important to their news work in general will be more likely to cover a press release with a disconfirming outside expert quote than a press release with a confirming outside expert quote or a press release with no outside expert quote.

H2. Science communicators who rate reliability of facts as very important to their news work in general will be more likely to cover a press release with a confirming outside expert quote than a press release with a disconfirming outside expert quote or no outside expert quote.

\section{Methods}

\section{Participants and data collection}

Science communicators were recruited to participate in an online survey experiment involving randomly assigned exposure to one of three different press release conditions. Experimental manipulation involved the presence or absence of a) confirming or b) disconfirming outside evidence in the form of an outside expert quote. Participants were recruited via social media (Twitter and Reddit posts) as well as via e-mail announcements to several science communication listservs, including the National Association of Science Writers listserv NASW-talk, the Psci-com science communication resource database listserv, and the Science Communicators of North Carolina (SCONC) listserv. Potential participants were invited to visit a link to the online survey hosted on Qualtrics. The survey introductory page described the survey as "being aimed at individuals who communicate news, including science news, in one form or another, including: location-based and freelance journalists; magazine writers and editors; scientific journal editorial and review article writers; bloggers and blog managers; radio communicators, podcast writers". Although participants were not recruited using probability sampling methods, the data reported originates from an experiment in the field, with online and social media based recruiting of a sample difficult to obtain in any other manner. Given the unlikelihood of 
obtaining a truly representative sampling frame of science communicators, and the power of experiments to reveal causal relationships, the findings reported herein are robust and valuable in guiding future research.

\section{Press release experimental manipulation}

Participants were randomly assigned to one of three press release conditions (1-2 page articles): (1) a control press release; (2) a press release containing confirming evidence from an outside expert source; (3) a press release containing disconfirming evidence from an outside expert source. The press releases reported on fabricated research conducted by researchers from the Rosenstiel School of Marine and Atmospheric Science at the University of Miami (choice of source made based on credibility of the school for climate-related science) and funded by the National Oceanic and Atmospheric Administration (NOAA), showing improvements to hurricane prediction modeling based on data weighting for recent warming atmospheric conditions. These sources of research and funding were considered prominent and highly reputable, chosen as such in order to prevent survey participants from making news decisions based primarily upon poor source credibility. Stimulus manipulation involved changes to only two paragraphs from the entire body of the control press release article. The confirming or disconfirming quotes in press release conditions (2) and (3) were provided by a supposed senior analyst with the Hurricane Forecast Improvement Project at the National Hurricane Center, a source with similar prominence and credibility as the researcher(s) who conducted the study. For example, the confirming quote condition added the following paragraph to the control article:

In order for the new model to be accepted on a national level, scientists at the National Hurricane Center, or NHC, will vet its predictions compared to those of traditional models. "The concept is sound, and the cross validation data are extremely promising", said Ethan Gibney, a senior analyst with the Hurricane Forecast Improvement Project at the National Hurricane Center, NHS. "This could be a valuable tool for forecasters."

The disconfirming quote condition added the following paragraph to the control article:

In order for the new model to be accepted on a national level, scientists at the National Hurricane Center, or NHC, must vet its predictions compared to those of traditional models. Scientists at NHC are worried that the new model assumes every hurricane is impacted by conditions of global climate change. "While the concept is interesting, it rests on the flawed premise that correlation equals causation", said Ethan Gibney, a senior analyst with the Hurricane Forecast Improvement Project at the National Hurricane Center, NHC. "That may explain the high accuracy rate when doing cross validation. But it doesn't mean that this will work when trying to predict future hurricanes." 


\section{Measures - outcomes: likelihood to cover and newsworthiness of the story}

After reading the 1-2 page press release, participants were asked questions adapted from Schmierbach [44] about their own likelihood and their news outlet's likelihood to pursue a story based on the information in the press release. Likelihood to pursue a story was measured in two separate questions on an 11-point scale from 0 ('not at all') to 10 ('very'): "How likely is it that you would write a story based on the study presented in the press release?" and "How likely is it that the media platform you work/write for would write a story based on the study presented in the press release?" (Likelihood to Cover). ${ }^{4}$ While the first question probes a respondent's personal news decision regarding the press release, the second question probes the respondent's sense of how likely his or her broader media outlet, editorial team, blogging network, etc. would be to cover the story. This second question makes sense in the context of sociology of the news, where journalists as well as bloggers make decisions of what to cover based on learned and socially validated news values and the sense of "I know it when I see it" coverage criteria [45].

Participants were then asked to indicate newsworthiness of the press release according to a variety of traditional news factors. Measurement of perceived newsworthiness consisted of a matrix survey instrument asking participants to, based on their reading, indicate on an 11-point scale, from 0 ('not at all') to 10 ('very'), how newsworthy the story in the press release was in terms of 8 different news factors: significance/public impact; meaningfulness/relevance to readers; novelty/unexpectedness; currency; conflict/controversy; unambiguity; facts/reliability of facts; human interest.

\section{Measures - moderators: importance of news factors in general}

Following newsworthiness and likelihood to cover survey questions, participants were asked to rate the 8 different news factors listed above according to "how important the following elements of newsworthiness are to you, as general guiding principles in your selection of stories" on an 11-point scale from 0 ('not at all') to 10 ('very'). It is important to note that while participants' general importance ratings of these 8 different news factors are considered in the data analysis as moderators of press release experimental effects, these survey questions were asked following participants' reading of the press release article. This was done in order to prevent any priming effects on outcome measures by forcing participants to express the importance they ascribe to particular news factors before reading the press release.

\footnotetext{
${ }^{4}$ Our analyses reveal significant press release effects only in the case of the outcome variable related to the participant's news outlet's likelihood to cover the story. Thus, we only report results for this variable, abbreviated "Likelihood to Cover".
} 


\section{Measures - demographic variables}

Participants finished the online questionnaire by answering questions related to their experience in science communication, years of professional experience in communication media, primary platform of communication work, education and gender. ${ }^{5}$ Survey data were analyzed in SPSS.

\section{Results}

\section{Descriptive data}

The final survey sample consisted of 330 participants. ${ }^{6}$ Of the final sample of participants, 162 were male and 168 were female. $82 \%(n=271)$ considered themselves to be science communicators, while $49 \%(n=164)$ considered themselves to be scientists by training. Nearly $68 \%$ of participants $(n=226)$ indicated that they are paid for their science communication work, and of these $31 \%(n=104)$ had been working in communication media on a professional level for more than 10 years, while less than $4 \%(n=13)$ had only been working on a professional level for less than a year. A majority of participants (59\%) indicated that they write stories about scientific research studies at least 2-3 times a month, and as much as daily (8\%). The breakdown of participants' predominant forms of communication work included: blog $(36 \%, \mathrm{n}=119)$; newspaper/online newspaper site $(20 \%$, $\mathrm{n}=70)$; magazine $(18 \%, \mathrm{n}=59)$; other $(18 \%, \mathrm{n}=61)$ e.g. various online science websites, books, government websites and television. Of those who indicated that blogging was the predominant form of their science communication work, $37 \%$ indicated that they are paid for this work. More than $95 \%(\mathrm{n}=314)$ of all participants indicated holding at least a Bachelor's degree (BA, AB, BS), with 39\% $(\mathrm{n}=129)$ holding Master's Degrees, $23 \%$ $(n=78)$ holding doctorate degrees and $5 \%(n=17)$ holding professional degrees (MD, DDS, etc.). Many of the relevant demographic characteristics of this sample are similar to those found in previous surveys of science journalists [2]. In a survey of over 500 science journalists by Nature in 2009, web stories (76.5\%) and blogs $(31.5 \%)$ were predominant formats for science journalists' work, as well as print $(83.7 \%)$. The fact that this survey experiment includes data from active science communicators in the field - a historically difficult sample to obtain — adds to the external validity of the results presented herein.

\footnotetext{
${ }^{5}$ Participants were also asked questions related to the importance they ascribe to a variety of other professional values, including factual accuracy, interest to readers, usefulness to readers, completeness, fairness to different views, diversity of views, and timely publication. These are not reported in the context of this particular study.

${ }^{6}$ A single multivariate outlier $(\mathrm{p}<.001)$ was deleted for dependent variables in the "likelihood to cover a story" measurement category. Three multivariate outliers $(\mathrm{p}<.001)$ were deleted for "likelihood to cover a story" dependent variables.
} 


\section{News factors ratings and influence of press release manipulation on newsworthiness}

Before the primary hypotheses could be addressed, it was important to test whether the press release manipulation successfully influenced perceived newsworthiness according to 8 different news factors (manipulation check). It was also necessary to test whether press release manipulation influenced perceived importance of these same news factors as overarching guiding principles to participants' selection of news. As long as press release manipulation did not influence the general importance participants ascribed to these different news factors, these importance ratings can be tested as moderators of press release main effects on likelihood to cover the story.

MANOVA analysis confirmed that the controversy-based press release manipulation (control vs. confirming quote vs. disconfirming quote) significantly influenced perceived newsworthiness in terms of specific news factors (Wilk's $\lambda=.84, \mathrm{~F}(16,472)=2.74$, $\left.\mathrm{p}<.001, \eta_{p}^{2}=.09\right)$. The univariate test for this analysis revealed that the outside quote manipulation significantly influenced perceived newsworthiness in terms conflict/controversy, where the press release with a disconfirming quote $(\mathrm{M}=5.66, \mathrm{SE}=.27)$ was perceived significantly more newsworthy in terms of conflict/controversy than the control $(\mathrm{M}=4.17, \mathrm{SE}=.27)$ or the press release with a confirming quote $(\mathrm{M}=3.89$, $\left.\mathrm{SE}=.27), \mathrm{F}(2,243)=74.57, \mathrm{p}<.001, \eta_{p}^{2}=.09\right)$. A manipulation check also confirmed that the press release with a disconfirming quote was perceived as significantly more controversial ("How controversial was the press release?") than the control release or the release with a confirming quote. These results confirm that the press release with a disconfirming quote was indeed perceived as more controversial, and more newsworthy in terms of conflict/controversy, than were the other two press release conditions. Press release quote manipulation had no significant impact on perceived newsworthiness in terms of the 7 other news factors measured. This presents an ideal case for isolating the impact of the conflict/controversy news factor on news judgments based on experimental manipulation of outside expert quotes in a climate science press release.

Additional MANOVA analyses also confirmed that press release quote manipulation (Wilk's $\lambda=.97, \mathrm{~F}(16,472)=.48, \mathrm{p}>.05, \eta_{p}^{2}=.02$ ) did not significantly influence science communicators' importance ratings of the 8 different news factors in general. This is an important prerequisite to testing general importance ratings of these different news factors as moderators of press release treatment effects on communicators' likelihood to cover the story. In other words, I can test whether science communicators who attribute high importance to conflict/controversy in general are most likely to cover a press release with a disconfirming outside expert quote, for example.

Table 1 lists perceived importance of all news factors in general, across all participants. Exploratory analysis revealed no significant differences in general importance ratings of conflict/controversy or reliability of facts between bloggers and non-bloggers, or between those who considered themselves scientists by training and those who didn't. For example, those who indicated they were scientists by training rated the importance of conflict/controversy as a news factor $(\mathrm{M}=6.44, \mathrm{SD}=2.5)$ only slightly but not sig- 
nificantly lower than did non-scientists $(\mathrm{M}=6.82, \mathrm{SD}=2.1)$. Bloggers rated currency (a topic currently in the spotlight of public concern $)(\mathrm{M}=7.71, \mathrm{SD}=2.20)$ and public impact $(\mathrm{M}=8.69, \mathrm{SD}=2.14)$ slightly but significantly less important than did non-bloggers (respectively: $\mathrm{M}=8.51, \mathrm{SD}=1.98, \mathrm{p}<.01 ; \mathrm{M}=9.24, \mathrm{SD}=1.66, \mathrm{p}<.01$ ), a finding that makes sense considering that bloggers may be under less pressure to write about current topics in the public sphere than are traditional journalists. Specifically newspaper journalists rated public impact $(\mathrm{M}=9.61, \mathrm{SD}=1.44)$, currency $(\mathrm{M}=8.97, \mathrm{SD}=1.59)$, human interest $(\mathrm{M}=8.33, \mathrm{SD}=1.76)$ and conflict/controversy $(\mathrm{M}=7.24, \mathrm{SD}=1.98)$ slightly but significantly more important than did bloggers (respectively: $\mathrm{M}=8.69, \mathrm{SD}=1.44$, $\mathrm{p}<.01 ; \mathrm{M}=7.71, \mathrm{SD}=2.20, \mathrm{p}<.001 ; \mathrm{M}=7.41, \mathrm{SD}=2.52, \mathrm{p}<.01 ; \mathrm{M}=6.51, \mathrm{SD}=2.51$, $\mathrm{p}<.05)$.

\begin{tabular}{|lcc|}
\hline News Factor & $\mathrm{M}$ & $\mathrm{SD}$ \\
\hline Facts/Reliability of facts & 9.93 & 1.49 \\
Meaningfulness/Relevance to readers & 9.34 & 1.63 \\
Significance/Public impact & 9.05 & 1.86 \\
Novelty/Unexpectedness & 8.55 & 1.81 \\
Currency & 8.23 & 2.09 \\
Human interest & 7.68 & 2.32 \\
Unambiguity & 7.05 & 2.49 \\
Conflict/Controversy & 6.66 & 2.33 \\
\hline
\end{tabular}

Note: News factors measured in data analysis on an 11-point scale, from 1(min) to 11(max).

Table 1. General News Factor Importance Means for all Participants.

These results indicate that while there is some degree of variability in news values among science journalists and science bloggers, by and large all respondents appear to place similar levels of importance on news factors including reliability of facts, novelty/unexpectedness, unambiguity, conflict/controversy, relevance to readers, and human interest. Reliability of facts is always rated of utmost importance, while conflict/controversy is consistently rated less important than most other news factors among survey participants on average. Similar importance ratings of reliability of facts and conflict/controversy, despite my survey respondents differing backgrounds, highlights that news values are widely shared and learned by communicators across media platforms.

\section{Outside expert quotes in a press release: role of conflict/controversy}

This study investigates whether the inclusion of confirming or disconfirming outside expert quotes in a climate science press release influences science communicators' likelihood to cover the story. News factors relevant to communicators' likelihood to pursue the story include conflict/controversy on one hand and reliability of facts on the other. Thus, 
general importance ratings of conflict/controversy and reliability of facts news factors were tested as moderators of the press release main effects.

A one-way ANOVA analysis revealed that participants perceived the media platforms they worked for to be more likely to write a story (Likelihood to Cover variable) based on the disconfirming quote press release $(\mathrm{M}=5.42, \mathrm{SE}=.34)$ than based on the confirming quote press release $(\mathrm{M}=4.47, \mathrm{SE}=.35), \mathrm{p}<.05$ (see Figure 2$)$. I conducted a multiple regression analysis to examine whether the general importance attributed to conflict/controversy as a news factor acted as a moderator of this press release treatment effect on Likelihood to Cover, using dummy-coded independent variables constructed with the 'disconfirming' quote press release as the reference group (see Table 2). Together, the variables in the model accounted for a marginally significant portion of the variance, $\bar{R}^{2}=.02, \mathrm{~F}(5,239)=2.23, \mathrm{p}=.05$. H1 was partially supported: there was a significant interaction effect between the control group dummy variable and the importance of conflict/controversy on likelihood to cover the story $(\beta=-.45, \mathrm{p}<.05)$. This interaction effect was probed using Andrew F. Hayes' Process SPSS macro for examining conditional moderation effects (Model 1) (see Figure 1) [46]. At one standard deviation above the mean of science communicators' importance ratings of conflict/controversy $(M=6.64$, $\mathrm{SD}=2.30$ ), participants indicated that the news outlet(s) they worked for would be significantly more likely to write a story based on the disconfirming quote press release $(\hat{y}=5.91)$ than based on the control press release $(\hat{y}=4.13)$, Conditional Effect $=-1.78$, S.E. $=.69, \mathrm{p}=.01 .^{7}$ This effect was significant only at values of importance ratings of conflict/controversy above $7.2(\mathrm{p}<.05)$, confirming the expected moderating relationship.

This interaction effect, as noted in Table 2, holds for communicators irrespective of communication platform. It is interesting to note, however, that an exploratory analysis revealed that the interaction effect between the control group dummy variable and the importance of conflict/controversy on likelihood to cover the story was pronounced when I looked only at respondents who indicated that they are scientists by training $(\beta=-.77$, $\mathrm{p}<.01)$. The same interaction effect is negligible for respondents who indicated that they are not scientists by training. This could be due to a lack of power when splitting the data analysis for scientists and non-scientists. However, it could also be that while nonscientist science communicators are more likely to cover a "controversial" press release than one without controversy on a general basis (see Figure 2), science communicators who are scientists by training must place high importance on conflict/controversy as a news factor for the same to be true.

\section{Outside expert quotes in a press release: role of reliability of facts}

I conducted a second multiple regression analysis to examine whether the general importance science communicators attribute to reliability of facts as a news factor acts as a

\footnotetext{
${ }^{7}$ Conditional effect of $\mathrm{X}$ on $\mathrm{Y}$ at values of the moderator $=8.94$; mean estimates based on Hayes Process analysis Model 1 using the following covariates set to their sample means: confirming dummy variable; interaction term between confirming dummy variable and conflict/controversy news factor.
} 


\begin{tabular}{|llll|}
\hline \multirow{4}{*}{ Variable } & $\begin{array}{l}\text { Likelihood } \\
\text { to Cover }\end{array}$ & \\
\cline { 2 - 4 } & $B$ & $\mathrm{P}$ & $(95 \% \mathrm{CI})$ \\
\hline Control dummy variable & .342 & .119 & $(-.584,5.119)$ \\
Confirm dummy variable & .131 & .560 & $(-2.071,3.816)$ \\
Importance of conflict/controversy & .260 & $.016^{*}$ & $(.065, .640)$ \\
Control*conflict/controversy & -.488 & $.031^{*}$ & $(-.863,-.043)$ \\
Confirm*conflict/controversy & -.321 & .170 & $(-.708, .126)$ \\
Multivariate analysis & $\left(\mathrm{r}^{2}=.04\right)$ & & \\
\hline
\end{tabular}

Note: $\beta$ is a standardized coefficient. Results shown reflect analysis across all participants. However, significant findings are fully reproducible even if I perform the analysis only for participants who indicate a "blog" as their predominant communication platform.

Table 2. Multiple regression analysis: predictors of Likelihood to Cover based on presence or absence of confirming of disconfirming quotes in a science press release.

\section{H1: Conditional Process Analysis}

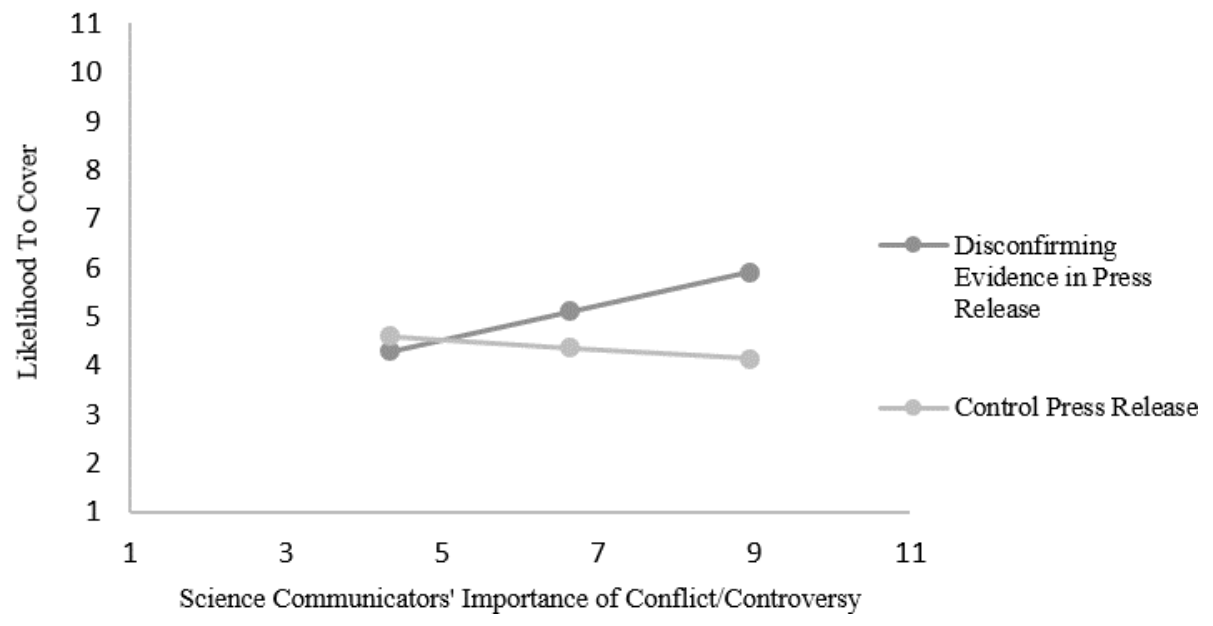

Figure 1. Graphical representation of Hayes' Process Analysis, with Mean \pm 1 SD Pick-a-Point conditioning, for importance of conflict/controversy moderation of stimulus effect on Likelihood to Cover.

moderator of press release treatment effects on Likelihood to Cover, using dummy-coded independent variables constructed with the disconfirming quote press release as the reference group (see Table 3). Together, the variables in the model accounted for a significant portion of the variance, $\bar{R}^{2}=.04, \mathrm{~F}(5,239)=2.79, \mathrm{p}<.05$. H2 was partially supported: there was a significant interaction effect between the confirming quote dummy variable and the importance of reliability of facts on Likelihood to Cover the story $(\beta=1.12$, $\mathrm{p}=.01$ ). This interaction effect was probed using Andrew F. Hayes' Process SPSS macro 


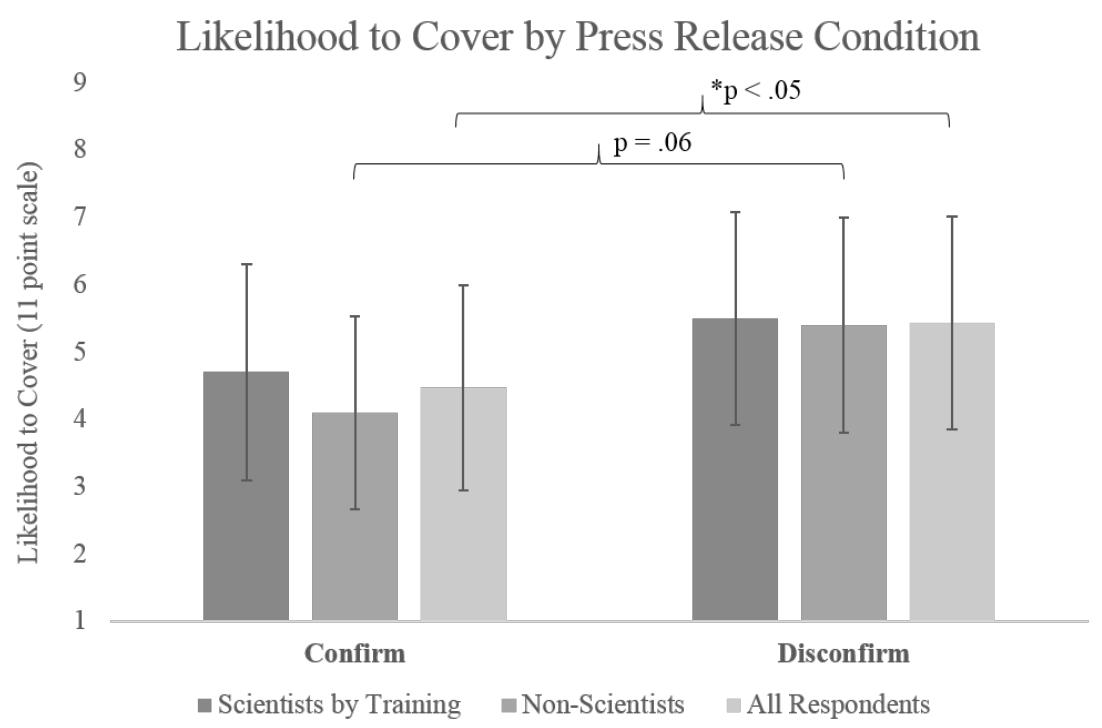

Figure 2. Means of Likelihood to Cover by press release condition (confirming quote press release versus disconfirming quote press release) for all respondents $(\mathrm{N}=165)$, respondents who are scientists by training $(\mathrm{N}=79)$, and respondents who are not scientists by training $(\mathrm{N}=84)$. Error bars represent standard deviation. Significant and marginally significant difference of means test p-values are shown.

for examining conditional moderation effects (Model 1) (see Figure 3) [46]. At the mean importance ratings of reliability of facts $(\mathrm{M}=9.89, \mathrm{SD}=1.55)$, participants indicated that the news outlet(s) they worked for would be significantly more likely to write a story based on the disconfirming quote press release $(\hat{y}=5.24)$ than based on the confirming quote press release $(\hat{y}=4.24)$, Conditional Effect $=-1.0$, S.E. $=.48, p<.05 .^{8}$ This effect was significant only at values of importance attributed to reliability of facts below 9.97 $(\mathrm{p}<.05)$, confirming the expected moderating relationship. High importance attributed to reliability of facts resulted in a loss of the treatment effect, such that participants no longer perceived the press release with a disconfirming quote more likely to be covered than a press release containing a confirming quote.

\section{Conclusions}

This study fills a gap in experimental research on the impact of outside expert quotes in science press releases on the news decisions of science communicators. As science public relations officers face increasing pressures to "beef up" their press releases, many researchers and active science communicators have wondered whether it would be useful to

\footnotetext{
${ }^{8}$ Conditional effect of $\mathrm{X}$ on $\mathrm{Y}$ at values of the moderator $=9.89$; mean estimates based on Hayes Process analysis Model 1 using the following covariates set to their sample means: control dummy variable; interaction term between control dummy variable and reliability of facts news factor.
} 


\begin{tabular}{|llll|}
\hline \multirow{4}{*}{ Variables } & $\begin{array}{l}\text { Likelihood } \\
\text { to Cover }\end{array}$ & \\
\cline { 2 - 4 } & $B$ & $\mathrm{p}$ & $(95 \% \mathrm{CI})$ \\
\hline Control dummy variable & -.678 & .208 & $(-11.522,2.525)$ \\
Confirm dummy variable & -1.262 & $.004^{*}$ & $(-14.108,-2.741)$ \\
Importance of reliability of facts & -.307 & $.005^{*}$ & $(-1.050,-.190)$ \\
Control*reliability of facts & .592 & .275 & $(-.309,1.082)$ \\
Confirm*reliability of facts & 1.120 & $.010^{*}$ & $(.179,1.320)$ \\
Multivariate analysis & $\left(\mathrm{r}^{2}=.06\right)$ & & \\
\hline
\end{tabular}

Note: $\beta$ is a standardized coefficient. Results shown reflect analysis across all participants.

Table 3. Multiple regression analysis: predictors of Likelihood to Cover based on presence or absence of confirming of disconfirming quotes in a science press release.

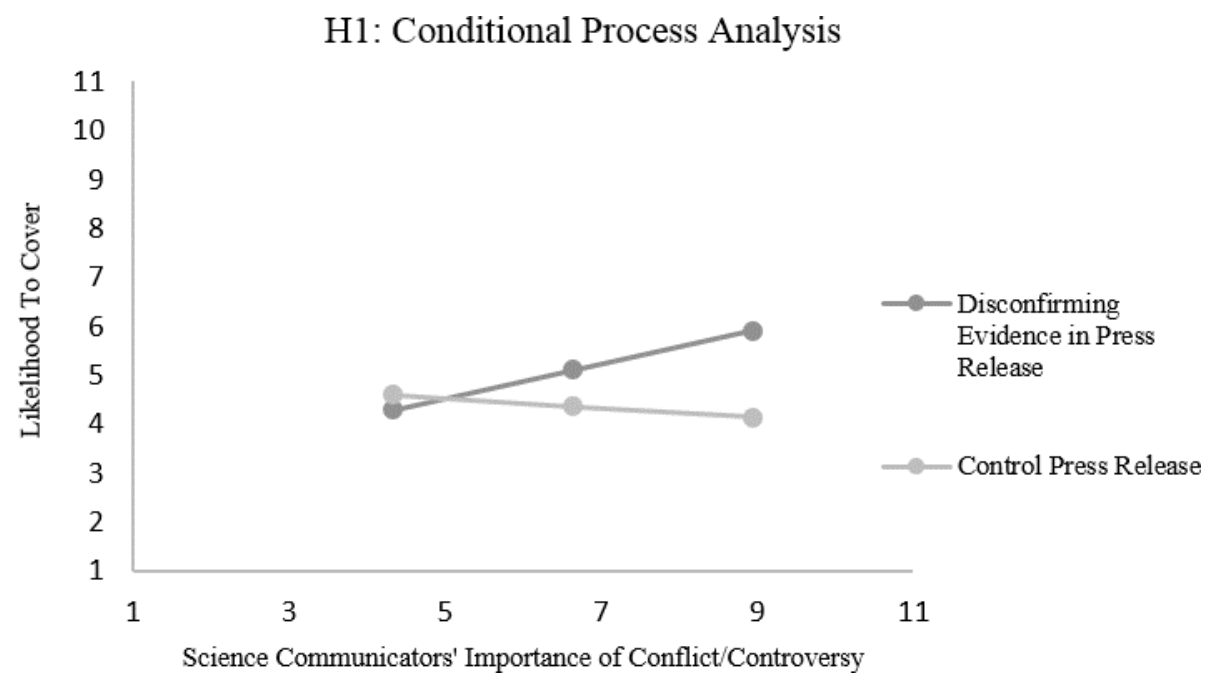

Figure 3. Graphical representation of Hayes' Process Analysis, with Mean \pm 1 SD Pick-a-Point conditioning, for importance of reliability of facts moderation of stimulus effect on Likelihood to Cover.

include outside expert quotes and contextual evidence [7, 8]. By experimentally adding either a confirming or disconfirming outside expert quote to a climate science press release, I was able to determine the role of such contextual evidence on news decisions, as well as the moderating influence of traditional news values on news decisions in this context.

I expected that the nature of an outside expert quote in a climate science press release would impact science communicators' perceived newsworthiness and likelihood to cover the story, commensurate with the news values of the individual communicator. This expectation was supported by the data. Overall, science communicators found a press release with a disconfirming quote from an outside expert, or one that introduced an element of scrutiny or controversy to the findings, more newsworthy, and were more likely 
to indicate coverage of such a release than a press release without an outside expert quote. But this effect depended on the news values of the individual science communicator. A science communicator attributing greater importance to conflict or controversy as a guiding principle in his or her work is most likely to cover a climate science press release with a disconfirming outside expert quote. On a more positive note, a science communicator placing relatively high importance on reliability of facts, which is highly valued in the scientific community, is less likely to cover such a press release, and is more likely to cover the same press release with a confirming outside expert quote instead.

It is important to note the usefulness as well as the limitation of investigating news decisions in the context of a press release describing climate science research. Preliminary findings of another study conducted by myself and colleagues, currently in manuscript phase, indicate that a disconfirming quote from an outside expert in a press release describing biological/medical science research actually acts as a deterrent to media coverage, at least for specialized science communicators who place high value on scientific replication. However, controversy may be a more important or salient criteria of newsworthiness for science communicators deciding whether to cover a climate science story, due to the controversial nature of global climate change in the news media today [30]. Future research should replicate this study in the context of other fields of research.

My results also indicate that controversy may guide news decisions in the area of climate science, even though when asked directly about their personal news values, science communicators generally rate conflict/controversy as less important than most other news factors. This may occur because journalists, beyond their personally held values, are trained in and embedded into (through broader editorial structures, etc.) a news environment that uses controversy or conflicting expert voices as heuristics for newsworthiness. News decisions have previously been found to rely heavily on a shared sense of "what is news" and the journalist's need for validation by other journalists [45]. Also, when constrained by the traditional pressures of news editors and the type of content perceived to be appropriate and "pitch-able" to the media platforms they work for, science communicators' news decisions might fall more in line with traditional news values such as conflict/controversy. It would make sense, then, for science communicators to use the disconfirming quote as a heuristic for story selection to a greater extent when asked about their news decisions from the point of view of their media platform than when asked from their personal view. Adding confirming or disconfirming quotes to a climate science press release significantly influenced science communicators' responses to the question "How likely is it that the media platform you work/write for would write a story based on the study presented in the press release?", while the same manipulation did not significantly influence personal likelihood to write a story based on the press release. While the scope of my analysis limits my ability to comment on exactly why communicators' personal decisions to write a story would be less influenced by contextual quotes in a press release than these same decisions from the less personal perspective of the communicators' respective media platforms, this finding is indicative of a third-person effect whereby participants perceive others to be more likely to be influenced by the 'controversial' press 
release than they perceive themselves to be. It is also likely that factors other than traditional news influence science communicators' personal likelihood to cover a story based on the presented news release [45]. These include the particular topic or theme of a given science communicators' blog, for example. Several participants sent follow-up e-mails after participation in my survey indicating that while they found the press release newsworthy, they wouldn't likely cover the story personally unless they lived in areas where hurricanes occurred. ${ }^{9}$ Thus, the Likelihood to Cover question phrased as "How likely is it that the media platform you work/write for would write a story..." may have been more sensitive to respondents' sense of what is newsworthy than the question phrased as personal likelihood.

The results of this study should also be interpreted in light of research showing that perceived newsworthiness and self-reported likelihood to cover a story do not necessarily correlate highly with what actually becomes news [47]. Future research in the form of case studies looking at the impact of outside expert quotes in science press releases on actual news coverage could confirm the findings from this study. However, I believe this study makes an important first step toward understanding how a growing practice of including outside expert quotes in science press releases may influence perceived newsworthiness and news coverage.

This study should be instrumental in guiding future research and in helping scientists, public relations writers and science journalists understand the factors that play a role in the process of getting scientific information from the lab to news story via the intermediary press release. For researchers, this study should provide the basis for future experimental and field studies looking at the effects of various elements in press releases on news judgments. For science press officers, this study delivers both good news and bad news. The good news is that science press release writers going to greater lengths to create content for public and media consumption that looks more like journalism need not be concerned that including honest and even critical outside expert quotes - contextual information of potentially great importance - will decrease news coverage of their releases. In fact, the opposite might be true. The bad news is that including such contextual information may not always result in greater news coverage only for more reliable research. Science press officers should be aware of the effect of including outside expert quotes in their press releases. While to scientists a disconfirming quote from an outside expert would likely indicate the need to wait for study replication and future research, to many news content producers this same quote might be a cue for news coverage in line with the traditional news values for conflict and controversy. Science press officers may be able to use this information to enhance the newsworthiness of their press releases through the inclusion of critical contextual information while also being careful that the message that reaches the public is that more information and research is needed.

According to one exploratory sub-sample analysis I've described, scientists by training may be less likely than non-scientist communicators to automatically lean toward cover-

\footnotetext{
${ }^{9}$ Hurricane research was the topic of manipulated press release in this study.
} 
age of a press release with a disconfirming quote and away from coverage of one with a confirming quote unless they personally rely heavily on conflict/controversy as a news value. Perhaps this is because scientists by training better understand that the lack of scientific consensus is an important sign that more research needs to be done. This highlights the potential for improved training for science news communicators on the balance needed between controversy as a news value and reliability of scientific research findings. Especially for publicly debated scientific issues such as climate change, scientific training for journalists may lead to a better understanding of how news decisions should include considerations of the research's scientific importance.

\section{Acknowledgments}

All stimulus articles were originally written by and created in collaboration with Matt Shipman, an experienced science communicator and public communication specialist at NC State in Raleigh, North Carolina. Acknowledgements also go to K. Lindsay Eaves for help in copy editing.

\section{References}

[1] A. Taylor (2014), The peril of the press release, attheinterface, http://attheinterface.wordpress.com/ 2014/05/21/the-peril-of-the-press-release/ (retrieved 8 October 2013).

[2] G. Brumfiel (2009), “Science journalism: Supplanting the old media?”, Nature 458: 274-277.

[3] D. Fahy and M.C. Nisbet (2011), “The science journalist online: Shifting roles and emerging practices”, Journalism 12: 778-793.

[4] R.B. Carver (2014), "Public communication from research institutes: is it science communication or public relations?”, JCOM 13(03): C01.

[5] C. Autzen (2014), "Press releases — the new trend in science communication”, JCOM 13(03): C02

[6] E. Weitkamp and T. Eidsvaag (2013), "Agenda Building In Media Coverage of Food Research: Superfoods coverage in UK national newspapers", Journalism Practice 8(6): 871-886, DOI: $10.1080 / 17512786.2013 .865966$.

[7] P. Edmonds (2013), "Science Press Releases: Good, Bad or Zombies?", http://peterdedmonds.blogspot.com/2013/01/science-press-releases-good-bad-or.html (retrieved 8 October 2013)

[8] N. Drake and P. Edmonds (2013), "Working towards better press releases: What do writers want?", ScienceOnline2013, Session 5C, http://scio13.wikispaces.com/Session+5C (if this page is not available, the link in reference [7] provides an overview of the Science Online 2013 session referenced in this paper.)

[9] J. Brechman, C-J. Lee and J.N. Cappella (2009), "Lost in Translation?: A Comparison of Cancer-Genetics Reporting in the Press Release and Its Subsequent Coverage in the Press", Sci. Commun. 30: 453-474.

[10] C. Mcinerney, N. Bird and M. Nucci (2004), "The Flow of Scientific Knowledge from Lab to the Lay Public: The Case of Genetically Modified Food”, Sci. Commun. 26: 44-74.

[11] R. Highfield (2000), "Selling Science to the Public", Science 289: 59. 
[12] G. Geller, B.A. Bernhardt, M. Gardner, J. Rodgers and N.A. Holtzman (2005), 'Scientists' and science writers' experiences reporting genetic discoveries: Toward an ethic of trust in science journalism”, Genetics in Medicine 7: 198-205.

[13] D. McQuail (2010), McQuail's mass communication theory, Sage publications.

[14] D. O’Neill and T. Harcup (2009), "News values and selectivity", in K. Wahl-Jorgensen and T. Hanitzsch eds., The handbook of journalism studies, Routledge, New York, U.S.A. .

[15] F. Badenschier and H. Wormer (2012), "Issue Selection in Science Journalism: Towards a Special Theory of News Values for Science News?”, Sociology of the Sciences Yearbook 28: 59-85.

[16] D. Nelkin (1995), Selling Science: How the Press Covers Science and Technology, W.H. Freeman \& Company, New York, U.S.A. .

[17] K. Arnold (2003), “Journals, the Press, and Press Releases: A Cozy Relationship", Science 26: 83.

[18] P. Brown (2012), "Nothing but the truth", EMBO reports 13: 964-967.

[19] C.E. Aronoff (1977), "Predictors of success in placing releases in newspapers", Public Relat. Rev. 2: 43-57.

[20] J.V. Turk (1986), "Public Relations' Influence on the News”, Newspaper Research Journal 7: 15-27.

[21] S.Y. Hong (2008), "The relationship between newsworthiness and publication of news releases in the media", Public Relat. Rev. 34: 297-299.

[22] H.J. Gans (1979), Deciding what's news: A study of CBS evening news, NBC nightly news, Newsweek, and Time, Northwestern Univ Press, U.S.A. .

[23] T. Gitlin (1980), The Whole World Is Watching: Mass Media in the Making and Unmaking of the New Left, University of California Press, U.S.A. .

[24] M. Lester and H. Molotch (1974), News as Purposive Behavior: On the Strategic Use of Routine Events, Accidents, and Scandals, National Emergency Training Center, U.S.A. .

[25] G. Tuchman (1978), Making news: A study in the construction of reality, Free Press, New York, U.S.A. .

[26] K. Viswanath, K.D. Blake, H.I. Meissner, N.G. Saiontz, C. Mull, et al. (2008), “Occupational Practices and the Making of Health News: A National Survey of U.S. Health and Medical Science Journalists", J. Health Commun. 13: 759-777.

[27] J. Galtung and M.H. Ruge (1965), “The Structure of Foreign News The Presentation of the Congo, Cuba and Cyprus Crises in Four Norwegian Newspapers”, J. Peace Res. 2: 64-90.

[28] J.E. Stryker (2002), "Reporting medical information: Effects of press releases and newsworthiness on medical journal articles' visibility in the news media", Preventive medicine 35: 519-530

[29] C. Russell (2006), "Covering controversial science: Improving reporting on science and public policy”, working paper, Joan Shorenstein Center on the Press, Politics and Public Policy, John F. Kennedy School of Government, Harvard University, U.S.A. .

[30] M.T. Boykoff and J.M. Boykoff (2007), "Climate change and journalistic norms: A case-study of US mass-media coverage”, Geoforum 38: 1190-1204.

[31] M.F. Weigold (2001), “Communicating Science”, Sci. Commun. 23: 164-193.

[32] L.M. Schwartz, S. Woloshin and L. Baczek (2002), "Media coverage of scientific meetings: Too much, too soon?”, J. Amer. Med. Assoc. 287: 2859-2863.

[33] M. Bertamini and M.R. Munafò (2012), "Bite-Size Science and Its Undesired Side Effects", Perspect. Psychol. Sci. 7: 67-71.

[34] J.M. Brechman, C-J. Lee and J.N. Cappella (2011), "Distorting Genetic Research About Cancer: From Bench Science to Press Release to Published News", J. Commun. 61: 496-513. 
[35] S. Woloshin and L.M. Schwartz (2002), "Press Releases”, J. Amer. Med. Assoc. 287: 2856-2858.

[36] J.C. Schroeder (2010), “Communicating Science: Press Releases at EHP”, Environ. Health. Persp. 11: 8 .

[37] L.M. Schwartz, S. Woloshin, A. Andrews and T.A. Stukel (2012), Influence of medical journal press releases on the quality of associated newspaper coverage: retrospective cohort study, Brit. Med. J. 344, DOI: 10.1136/bmj.d8164.

[38] A.C. Saguy and R. Almeling (2008), "Fat in the Fire? Science, the News Media, and the "Obesity Epidemic", Sociological Forum 23: 53-83.

[39] M. Schudson (2003), The sociology of news, W.W. Norton \& Company, New York, U.S.A. .

[40] R.V. Ericson, P.M. Baranek and J.B. Chan (1989), Negotiating control: A study of news sources, Milton Keynes, Open University Press Milton Keynes.

[41] M.W. Bauer, S. Howard, R. Ramos, Y. Jessica, L. Massarani and L. Amorim (2013), Global science journalism report: working conditions \& practices, professional ethos and future expectations, Science and Development Network, London, U.K. .

[42] T. Caulfield and C. Condit (2012), "Science and the sources of hype", Public Health Genomics 15 : 209-217.

[43] Duke University (2012), "Singing mice show signs of learning”, ScienceDaily, http://www.sciencedaily.com/releases/2012/10/121010172128.htm (retrieved 8 October 2013).

[44] M. Schmierbach (2005), "Method Matters: The Influence of Methodology on Journalists' Assessments of Social Science Research", Sci. Commun. 26: 269-287.

[45] W. Donsbach (2004), "Psychology of News Decisions: Factors behind Journalists' Professional Behavior”, Journalism 5: 131-157.

[46] A.F. Hayes (2013), Introduction to mediation, moderation, and conditional process analysis: A regression-based approach, Guilford Press, U.S.A. .

[47] P.J. Shoemaker and A.A. Cohen (2006), News around the world: Practicioners, content and the public, Routledge, Oxford, U.K. .

\section{Author}

Paige Brown Jarreau is a Ph.D. candidate in the Manship School of Mass Communication at Louisiana State University in Baton Rouge, Louisiana. She also holds Bachelor of Science and Master of Science degrees in Biological and Agricultural Engineering from Louisiana State University. Her research focuses on the intersection of science communication, science journalism and new media. E-mail: Pbrow11@tigers.lsu.edu

HOW TO CITE: P. Brown Jarreau, "When quotes matter: impact of outside quotes in a science press release on news judgment", JCOM 13(04)(2014)A02. 